\title{
Dissolution Equilibrium and In Situ Growth of HMCM-49 in Aqueous- Phase Reaction
}

Xinde Sun*, Yingli Wang, Yanli He, Yue Yang, Shutao Xu, Shukui Zhu, Miao Yang, and Zhongmin Liu*

National Engineering Laboratory for Methanol to Olefins, Dalian National Laboratory for Clean Energy, Dalian Institute of Chemical Physics, Chinese Academy of Sciences, Dalian 116023, P.R. China

*Correspondence to: Sunxd@dicp.ac.cn (X. Sun), liuzm@dicp.ac.cn (Z. Liu)

\section{This PDF file includes:}

Experimental procedure

Calculation method of dissolution rate

Figure S1

Table S1

Reference 1-3

\section{Experimental procedure}

$\underline{\text { Materials }}$

NH 4 ZSM-5 $\left(\mathrm{SiO}_{2} / \mathrm{Al}_{2} \mathrm{O}_{3}=44\right)$ was purchased from Nankai University Catalyst Company, China.

AR grade EGME (>99.0 wt\%) was purchased from Sinopharm Chemical Reagent Co., Ltd. Industrial grade EGME (>99.0 wt\%) was purchased from Lyondell Chemical Company.

\section{Catalyst preparation}

MCM-49 $\left(\mathrm{SiO}_{2} / \mathrm{Al}_{2} \mathrm{O}_{3}=21\right)$ was synthesized by method described elsewhere. ${ }^{1}$ The powder was extruded to trefoil shape of $\varphi 1.6 \mathrm{~mm}$ together with $30 \mathrm{wt} \% \mathrm{Al}_{2} \mathrm{O}_{3}$ binder and broken to $2-4 \mathrm{~mm}$ length. Then the catalyst underwent calcination at $540{ }^{\circ} \mathrm{C}$ for $3 \mathrm{hrs}$ to remove templates, ammonium ion exchange with $0.5 \mathrm{M} \mathrm{NH}_{4} \mathrm{Cl}$ solution, calcination at $500{ }^{\circ} \mathrm{C}$ for $3 \mathrm{hrs}$ to remove ammonia, and hydrothermal treatment at $550{ }^{\circ} \mathrm{C}$ for $2 \mathrm{hrs}$ and HMCM-49 catalyst was got.

NH $4 \mathrm{ZSM}-5\left(\mathrm{SiO}_{2} / \mathrm{Al}_{2} \mathrm{O}_{3}=44\right)$ powder was extruded to cylinder shape of $\varphi 1.5 \mathrm{~mm}$ together with 20 wt $\% \mathrm{Al}_{2} \mathrm{O}_{3}$ binder and broken to $2-4 \mathrm{~mm}$ length. Then the catalyst underwent calcination at $550{ }^{\circ} \mathrm{C}$ for $3 \mathrm{hrs}$ to remove ammonia, and hydrothermal treatment at $600{ }^{\circ} \mathrm{C}$ for $2 \mathrm{hrs}$ and HZSM-5 catalyst was got. Long term catalytic test and analysis

$2342 \mathrm{hrs}$ long term catalytic test on EGME hydrolysis to EG was carried out in an up-flow fixed-bed reactor (ID $14 \mathrm{~mm}$ ) with a thermal couple tube (OD $3 \mathrm{~mm}$ ) inside and electric heating belt outside. The 
catalyst loading was $53 \mathrm{ml}$ and height of catalyst bed was $35.2 \mathrm{~cm}$. The test was shut down 3 times lasting 1 - 4 days which showed no evident effect to the catalytic performance.

Reaction conditions were as follows. Aqueous solution of EGME (AR grade for 0 - $373 \mathrm{hr}$ and 1928 $2342 \mathrm{hr}$, industrial grade for 373 - $1928 \mathrm{hr}$ ) with $\mathrm{H}_{2} \mathrm{O} / \mathrm{EGME}=4$ (mol/mol) was used as feed; LHSV, $0.37 \mathrm{ml} /$ gcat $\bullet$; P, 2.0 MPa. The temperature profile of the catalyst bed was arranged to be a parabolic shape. $\mathrm{T}_{\mathrm{M}}$ (maximum of $\mathrm{T}$ profile) was raised from $190{ }^{\circ} \mathrm{C}$ to $212{ }^{\circ} \mathrm{C}$ by 8 steps. Under these conditions, the reaction mixture was kept in liquid phase in the whole catalyst bed.

The liquid effluent was analyzed on a Agilent 7890 GC equipped with a FFAP capillary column (ID $0.53 \mathrm{~mm}$, length $30 \mathrm{~m}$ ) connected to a FID detector. The selectivity data were based on carbon number while amount of product DME was calculated according to conservation of ratio of methoxyl to ethoxyl group.

\section{Catalytic test for residual activity}

2 - $4 \mathrm{~g}$ tested catalyst was loaded in the same rector as long term catalytic test. Temperature difference of the catalyst bed was $<3{ }^{\circ} \mathrm{C}$. Aqueous solution of AR grade EGME of was used as feed.

\section{Catalytic test for comparing HZSM-5 and HMCM-49}

8 - $10 \mathrm{~g}$ catalyst was loaded in the same rector as long term catalytic test. Temperature difference of the catalyst bed was $\sim 3{ }^{\circ} \mathrm{C}$. Aqueous solution of AR grade EGME of was used as feed.

\section{$\underline{\text { Static dissolution experiment }}$}

A 200ml autoclave loading $1 \mathrm{~g}$ HMCM-49 catalyst and $100 \mathrm{ml}$ reaction effluent of EGME hydrolysis was placed in an oven at $210^{\circ} \mathrm{C}$ for $2000 \mathrm{hrs}$.

\section{$\underline{\text { ICP analysis }}$}

The ICP analysis was carried out on PerkinElmer ICP-OES 7300 DV.

\section{Catalyst characterization}

XRF was carried on PANalytical Axios Advanced X-ray fluorescence spectrometer.

Powder XRD was carried on PANalytical X'Pert PRO X-ray diffractometer with $\mathrm{Cu}$ K $\alpha$ radiation operating at $40 \mathrm{kV}$ and $40 \mathrm{~mA}$. Crystallinity of MCM-49 was based on XRD peak intensity of $2 \theta=26^{\circ}$.

${ }^{29}$ Si MAS NMR spectra were performed on a Bruker Avance III 600 solid-state NMR spectrometer equipped with a $4 \mathrm{~mm}$ double resonance probe with a spinning rate of $8 \mathrm{kHz}$ using a high-power proton decoupling sequence. The chemical shift was referenced to kaolinite at $-91.5 \mathrm{ppm}$ as a secondary reference.

\section{Calculation method of dissolution rate}

The dissolution rates $\left(\mathrm{r}_{\mathrm{Si}}\right.$ and $\left.\mathrm{r}_{\mathrm{Al}}\right)$ were calculated as follow:

$$
r_{x}=\frac{c_{x-E f f} \times L H S V}{C_{x-C a t}}
$$

Where, $\mathrm{r}_{\mathrm{x}}$ is dissolution rate $\left(\mathrm{h}^{-1}\right), \mathrm{x}=\mathrm{Si}$ or Al.

$\mathrm{c}_{\mathrm{x} \text {-Eff }}$ is $\mathrm{Si}$ or $\mathrm{Al}$ content in effluent $(\mathrm{mg} / \mathrm{l})$.

$18.7 \%$ for HMCM-49.

$$
\mathrm{c}_{\mathrm{x}-\mathrm{Cat}} \text { is } \mathrm{Si} \text { or } \mathrm{Al} \text { weight content in catalyst. Si 36.0\%, Al 12.2\% for HZSM-5; Si 30.2\%, Al }
$$




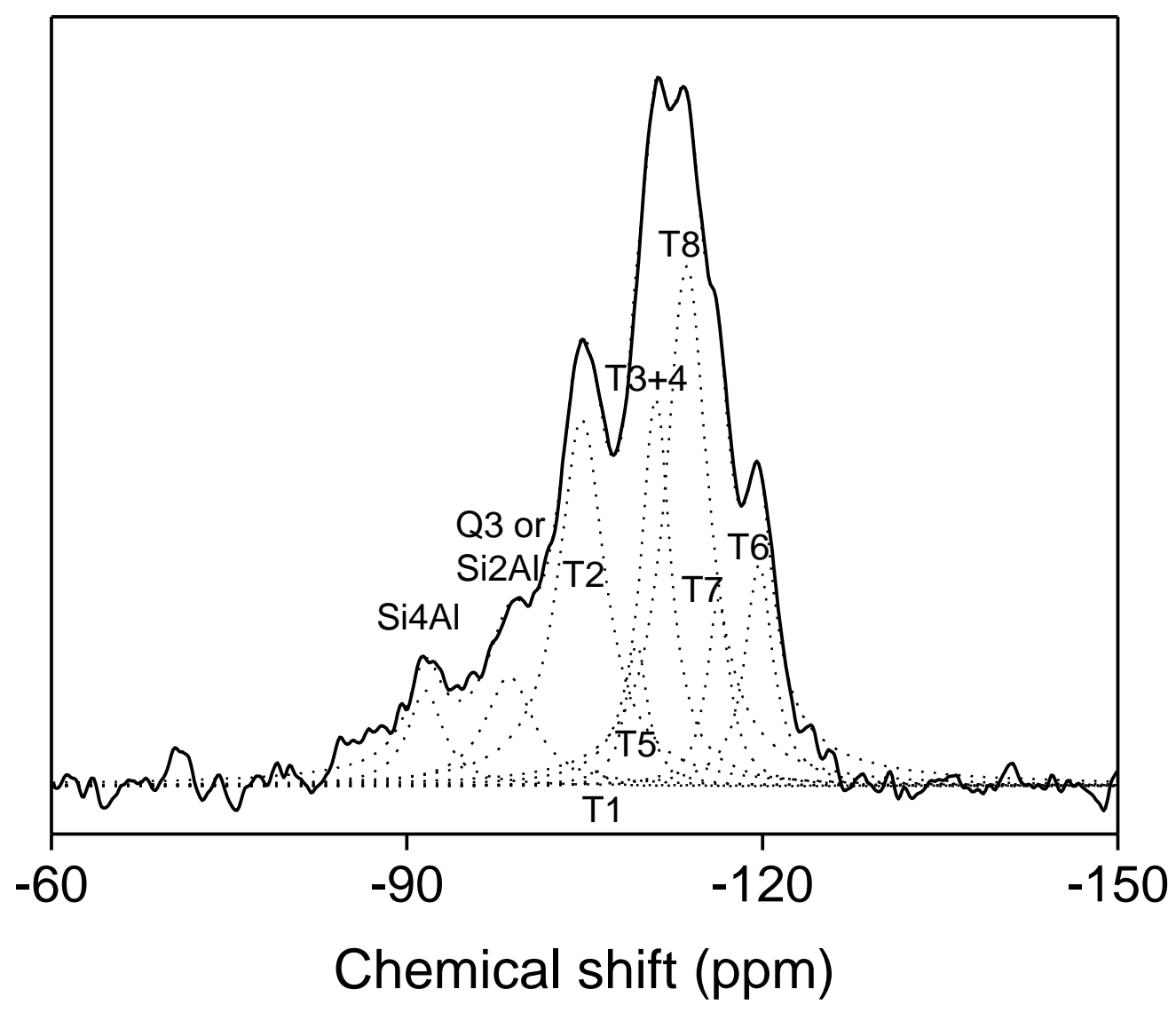

Figure S1. Decomposition of ${ }^{29}$ Si NMR spectrum over sample $H$. 
Table S1. Assignment of ${ }^{29} \mathrm{Si}$ NMR spectrum over sample $\mathrm{H}$ consulting references ${ }^{2,3}$

\begin{tabular}{lll}
\hline $\begin{array}{l}\delta \\
(\mathrm{ppm})\end{array}$ & $\begin{array}{l}\text { Int. } \\
(\%)\end{array}$ & Site \\
\hline-91.6 & 4.6 & $\mathrm{Si} 4 \mathrm{Al}(\mathrm{kaolinite})$ \\
-98.6 & 7.3 & $\mathrm{Q}_{3}$ or $(\mathrm{Si} 2 \mathrm{Al})$ \\
-104.8 & 23.2 & $\mathrm{~T} 2(\mathrm{Si} 1 \mathrm{Al})$ \\
-106.2 & 0.3 & $\mathrm{~T} 1(\mathrm{Si} 1 \mathrm{Al})$ \\
-109.4 & 4.3 & $\mathrm{~T} 5(\mathrm{Si} 0 \mathrm{Al})$ \\
-111.0 & 15.9 & $\mathrm{~T} 3+\mathrm{T} 4(\mathrm{Si} 0 \mathrm{Al})$ \\
-113.6 & 30.0 & $\mathrm{~T} 8(\mathrm{Si} 0 \mathrm{Al})$ \\
-116.3 & 5.9 & $\mathrm{~T} 7(\mathrm{Si} 0 \mathrm{Al})$ \\
-119.7 & 8.5 & $\mathrm{~T} 6(\mathrm{Si} 0 \mathrm{Al})$ \\
\hline
\end{tabular}

\section{References}

(1) Wang, L.; Tian, P.; Yuan, Y.; Yang, M.; Fan, D.; Zhou, H.; Zhu, W.; Xu, S.; Liu, Z. Seed-assisted synthesis of high silica ZSM-35 through interface-induced growth over MCM-49 seeds. Microporous Mesoporous Mater. 2014, 196, 89-96.

(2) Buhl, J. C.; Hoffmann, W.; Buckermann, W. A.; Muller-Warmuth, W. The crystallization kinetics of sodalites grown by the hydrothermal transformation of kaolinite studied by ${ }^{29}$ Si MAS NMR. Solid State Nucl. Magn. Reson. 1997, 9, 121-128.

(3) Vuono, D.; Pasqua, L.; Testa, F.; Aiello, R.; Fonseca, A.; Koranyi, T. I.; Nagy, J. B. Influence of $\mathrm{NaOH}$ and $\mathrm{KOH}$ on the synthesis of MCM-22 and MCM-49 zeolites. Microporous Mesoporous Mater. 2006, 97, 78-87. 